\title{
Pollination methods, stigma receptivity and pollen tube growth in Eucalyptus argophloia
}

\author{
By Bruce W. RAndall ${ }^{1), *}$, David A. WAlton ${ }^{1)}$, David J. LeE ${ }^{1,2)}$ and Helen M. WAllace ${ }^{1)}$
}

(Received $18^{\text {th }}$ November 2011)

\begin{abstract}
Eucalyptus argophloia Blakely (Western white gum) has shown potential as a commercial forestry timber species in marginal environments of north-eastern Australia. We measured early pollination success in Eucalyptus argophloia to compare pollination methods, determine the timing of stigma receptivity and compare fresh and stored pollen. Early pollination success was measured by counting pollen tubes in the style of E. argophloia 12 days after pollination. We compared the early pollination success of 1) Artificially Induced Protogyny (AIP), one-stop and three-stop methods of pollination; 2) flowers pollinated at 2 day intervals between 2 days before and 6 days after anthesis and 3) fresh pollen and pollen that had been stored for 9 months.

Our results show significantly more pollen tubes from unpollinated AIP and AIP treatments than either the one-stop pollination or three-stop pollination treatments. This indicates that self-pollination occurs in the unpollinated AIP treatment. There was very little pollen tube growth in the one-stop method indicating that the three-stop method is the most suitable for this species.

Stigma receptivity in $E$. argophloia commenced six days after anthesis and no pollen tube growth was observed prior to this. Fresh pollen resulted in pollen tube growth in the style whereas the stored pollen resulted in a total absence of pollen tube growth.

We recommend that breeding programs incorporating E. argophloia as a female parent use the three-stop pollination method, and controlled pollination be carried out at least six days after anthesis using fresh pollen.
\end{abstract}

Key words: one-stop pollination, three-stop pollination, artificially induced protogyny, stored pollen.

\section{Introduction}

Forestry plantations in northern Australia are forecast to expand mainly in areas currently considered marginal for plantation forestry (NGUGI et al., 2004a; LEE et al., 2010). Consequently species suitable for these regions need to be developed to satisfy increasing demand (LEE et al., 2005; VENN, 2005).

In some species of Eucalypts, hybrids have superior growth and a wider environmental range than the parent species (LeE et al., 2009, DiCKINSON et al., 2010). Hybrids are produced with a range of pollination techniques including three-stop pollination (VAN WYK, 1977), one-stop pollination (HARBARD et al., 1999;

1) Faculty of Science, Health and Education, University of the Sunshine Coast, Maroochydore Queensland, 4558, Australia.

2) Department of Employment, Economic Development and Innovation (DEEDI), Gympie, Queensland 4570, Australia.

*) Author for correspondence: BRUCE RANDALL.

Phone: +61754565018. E-Mail: brandall@usc.edu.au
TRINDADE et al., 2001) and artificially induced protogyny (AIP) (PATTERSON et al., 2004; Assis et al., 2005).

The three-stop pollination technique requires three separate visits: 1) bud emasculation, 2) pollination and 3) bag removal. Ripe buds are emasculated and bagged to prevent open pollination, pollen is applied to receptive stigmas, flowers are re-bagged, and bags are removed after fertilization (VAN WYK, 1977; MONCUR, 1995; SEDGLeY and SMith, 1989; Delaporte et al., 2001). The three-stop pollination method ensures cross pollination with a known male parent and prevents self-pollination or unknown cross pollination. This system has labour and cost disadvantages (VAN WYK, 1977), with an increased risk of damage to buds causing increased mortality (DiCKINSON et al., 2010).

The one-stop pollination technique requires by definition only one visit; however two visits may be needed to eliminate any possibility of contamination. The immature buds and open flowers are removed, mature buds are emasculated, and the style is cut to remove the stigma (HARBARD et al., 1999; TRINDADE et al., 2001; POTTS and Dungey, 2004). Pollen is then immediately applied to the cut surface, and if foreign pollen is a concern the style is bagged to prevent contamination (TRINDADE et al., 2001; PotTs and Dungey, 2004). The bags are normally removed about a week later. Removal of the tip of the style during the one-stop pollination method causes an exudate, reduces the problem of applying pollen when the stigma is not receptive (PATTERSON et al., 2004) and may overcome incompatibility reactions that block pollen tube growth (TRINDADE et al., 2001). This method also reduces the number of visits and consequently has cost advantages over the traditional three-stop method (Williams et al., 1999; PotTs and DungeY, 2004).

The AIP technique does not require emasculation of the flower buds. The tip of the operculum and the stigma are cut-off and pollen is applied to the cut surface of the upper style. The AIP techniques has similar advantages to one-stop pollination, however there are increased risks of self-pollination because the flowers are not emasculated (Assis et al., 2005; Dickinson et al., 2010; HoRsley et al., 2010). Cutting the style allows pollination before the stigma is receptive and increases the quantity of seed produced in E. globulus (WILLIAMS et al., 1999; PATTERSON et al., 2004) and E.grandis, E. smithii and E. macarthurii (HORSLEY et al., 2010), however WILLIAMS et al. (1999), found this treatment to be unsuccessful for $E$. nitens. The AIP method also reduces the number of visits and consequently has cost advantages over the one-stop pollination method. DiCKINSON et al. (2010) also found that this process was quicker allowing a significant reduction in cost. 
Eucalyptus argophloia Blakely (Western white gum or Chinchilla white gum) is endemic to south eastern Queensland and has very limited natural distribution (BROOKER and KLEINIG, 2004) northeast of Chinchilla in south-eastern Queensland. This species is classified as 'vulnerable' under the Queensland Nature Conservation Act (1992) so harvesting or clearing of naturally occurring trees is restricted. It is a large tree $(40 \mathrm{~m})$ with fast growth rates and produces strong durable timber (NGUGI et al., 2004b; BolAND et al., 2006). E. argophloia has potential as a forestry species because of its growth, form, and stem borer resistance (LEE et al., 2011), its adaptation to low rainfall environments, and ability to withstand drought and tolerance of salinity (House et al., 1998). Currently approximately 5000 hectares of $E$. argophloia plantation have been established in marginal environments in Australia's subtropics for timber and carbon sequestration.

E. argophloia has small buds to $0.4 \times 0.4 \mathrm{~cm}$ (BROOKER and KLEINIG, 2004) and little information is available about pollination methods for the species. The efficiency of controlled three-stop pollination depends on applying the pollen synchronously with stigma receptivity. The period between anthesis and stigma receptivity varies between species. In Eucalyptus subgenus Symphyomyrtus for example $E$. cladocalyx is receptive at 10 days (Ellis and SEDGley, 1992), E. grandis 4-6 days and E. regnans 10-14 days (GRIFFIN and HAND, 1979; Assis et al., 2005) post anthesis. Exact timing of flower development may also vary due to environmental and seasonal conditions or genotypes (PATTERson et al., 2004). Prior to this study, the timing of stigma receptivity of $E$. argophloia had not been determined.

Stored pollen is often required for pollination when producing seed with known parentage or when producing hybrids as species or selected trees within a species that often flowers asynchronously. Pollen quality and viability has been found to decrease with age and storage conditions (HORSLEY et al., 2007). The effect of storage on viability of $E$. argophloia pollen is also not known.

In many studies, pollen viability is assessed by the ability of pollen tubes to develop in-vitro on an artificial medium. However, in-vitro testing may not reflect pollen tube growth within styles due to chemical differences between the artificial media and the extracellular matrix of the style (LORD, 2000), or incompatibility between maternal parent and pollen (PоTтs and Dungey, 2004; HoRsley et al., 2007). Alternatively examination of in-vivo pollen tubes more accurately reflects early pollination success. Seed set is influenced by many confounding environmental factors, such as animal and insect attack and resource availability (SETTERFIELD and Williams, 1996) and genetic factors (PotTs et al., 2007). Consequently seed set may also not be an accurate measure of pollination success.

In this study, we aim to identify the best methods of pollinating $E$. argophloia for breeding programs, in particular hybrid breeding programs. We used pollen tube growth in the style of E. argophloia to assess early pollination success without the confounding factors caused by using an in-vitro growth medium or measuring seed set. We compared the one-stop method; the three-stop method; the AIP method; and an AIP without pollination control treatment. We also examined the timing of stigma receptivity, and compared viability of stored and fresh pollen by the differences in the number of pollen tubes.

\section{Materials and Methods}

\section{General Methods}

Pollination studies of $E$. argophloia were conducted at the DEEDI, Forestry Complex at Gympie southeast Queensland (26 $\left.{ }^{\circ} 11^{\prime} \mathrm{S}, 152^{\circ} 40^{\prime} \mathrm{E}\right)$ during December 2007 and January 2008. Controlled pollinations were carried out on at least ten individual flowers per tree, for each treatment on two Eucalyptus argophloia trees to determine 1) the best method for pollinating $E$. argophloia, 2) the optimum timing for stigma receptivity, and 3) to compare stored and fresh pollen.

All pollinations were carried out with an extracted pollen poly-mix from three unrelated trees except where stated otherwise.

Pollen tube growth in styles was investigated by fluorescence microscopy. Styles were collected 12 days after each respective pollination and stored in 1 part acetic acid: 3 parts ethanol. Samples were rinsed and autoclaved in a $10 \%$ sodium sulphite solution to soften, then washed in deionised water and placed in decolourised aniline blue (MARTIN, 1959). The cuticle of each style was dissected longitudinally, the style squashed and examined for pollen tube growth with a fluorescence microscope (Zeiss Axioskop 2 MOT). The number of pollen grains on the stigma, and pollen tubes in the upper style, mid style and lower style were counted.

\section{Pollination Methods}

Two $E$. argophloia trees received four treatments: 1) the one-stop method as described by WILLIAMS et al. (1999); 2) the three-stop method as described by VAN WYK (1977); 3) the AIP method as described by Assis et al. (2005) and 4) an AIP method without pollination (as a control).

Flowers for one-stop pollination and three-stop pollination were emasculated just prior to anthesis, when the operculum changed from green to brown, approximately two days prior to operculum lift. The opercula were removed and individual flowers emasculated using a curved scalpel blade. All other buds (in each inflorescence) on each branch were removed at emasculation. After emasculation, each branch was bagged with a polyester pollination bag to exclude pollinators and foreign pollen. At the same stage, flowers for AIP and the AIP unpollinated treatments were treated by removing the tip of the operculum and stigma. Pollen was immediately applied to the cut style in the AIP treatment and the branch was bagged with a polyester pollination bag as above.

Flowers pollinated with the three-stop pollination method were pollinated once only, approximately seven days after emasculation when stigmas had visible exudates. Flowers pollinated with one-stop pollination and AIP methods were pollinated on the day of emascula- 
tion. A poly-mix of freshly extracted pollen was applied using a moistened match head. Each match was discarded after use for pollen transfer. Branches were then rebagged until collection of the flowers for pollen tube analysis.

\section{Timing of Stigma Receptivity}

To analyse the timing of sigma receptivity of $E$. argophloia, 60 flowers were emasculated 2 days prior to anthesis and pollinated in stages using the 3-stop pollination method (SEDGLEY and SMITH, 1989). A polymix of freshly extracted pollen was applied to 10 stigmas once only on one of 5 time points: 1) the day of emasculation, approximately (2 days before anthesis); 2) two days later (day 0 , anthesis); 3 ) four days later (2 days post anthesis); 4) six days later (4 days post anthesis); $5)$ eight days later (6 days post anthesis). Styles were collected twelve days after the respective pollination. For example flowers pollinated on days $-2,0,+2,+4$ and +6 ; were collected at $10,12,14,16$ and 18 days after anthesis.

\section{Comparison of Stored and Fresh Pollen}

Flowers of $E$. argophloia received three different treatments: 1) fresh pollen applied directly from the anthers of two unrelated trees; 2) freshly extracted pollen polymix from three unrelated pollen parents (the anthers were removed from the buds and desiccated for 24-48 $\mathrm{h}$ to promote dehiscence); 3) a polymix of three trees of $E$. argophloia, pollen extracted as in treatment 2 then stored for nine months at $5^{\circ} \mathrm{C}$ in gel capsules. Trees were pollinated once only, using the three-stop method approximately 9 days after emasculation when stigmas had visible exudate.

\section{Statistical analysis}

All data were analysed using SPSS version 17 (SPSS Science, Chicago). Data from each experiment were nonparametric, so differences between treatments were analysed by Kruskal-Wallis and Mann Whitney U-tests where differences were significant. A Bonferroni correction was used to determine the appropriate level of significance (SOKAL and ROHLF, 1995).

\section{Results}

\section{Pollination Methods}

The highest number of pollen tubes in the upper style, mid style and lower style occurred in both the AIP treatment and the unpollinated AIP treatment. Both of these had significantly higher numbers of pollen tubes than the one-stop treatment in the upper and middle style $(\mathrm{P}=0.01, \mathrm{P}=0.018$ respectively), but not significantly higher than the three-stop treatment, and were significantly higher than both the one stop and three stop in the lower style $(P=0.014)$. There were no significant differences between the one-stop and the three-stop pollination treatments (Table 1). No pollen tubes were observed in the upper, middle and lower style for the one-stop treatment and the lower style for the threestop treatment (Table 1).

\section{Timing of Stigma Receptivity}

On the styles that were pollinated six days after anthesis, pollen grains were observed adhering to the stigma (mean 2.83) and pollen tubes were observed in the upper (mean 3.58), middle (mean 3.33) and lower style (mean 1.67); in contrast pollen grains failed to

Table 1. - The mean number of pollen grains observed and the mean number of pollen tubes in the style of Eucalyptus argophloia twelve days after pollination using the one-stop method, the three-stop method, artificially induced protogyny (AIP) method and the artificially induced protogyny unpollinated (AIP unpollinated) control treatment. Means in each row with different letters are significantly different (Kruskal-Wallis).

\begin{tabular}{lccccl}
\hline & $\begin{array}{c}\text { One-stop } \\
(\mathrm{n}=27)\end{array}$ & $\begin{array}{c}\text { Three-stop } \\
(\mathrm{n}=27)\end{array}$ & AIP $(\mathrm{n}=25)$ & $\begin{array}{c}\text { AIP unpollinated } \\
(\mathrm{n}=21)\end{array}$ & P value \\
\hline Pollen Grains & 2.56 & 1.41 & 3.64 & 3.33 & $\mathbf{n s}$ \\
Pollen Tubes Upper style & $0.07 \mathrm{a}$ & $0.19 \mathrm{ab}$ & $1.00 \mathrm{~b}$ & $5.10 \mathrm{~b}$ & $\mathbf{0 . 0 1}$ \\
Pollen Tubes Mid-Style & $0.00 \mathrm{a}$ & $0.11 \mathrm{ab}$ & $0.76 \mathrm{~b}$ & $3.57 \mathrm{~b}$ & $\mathbf{0 . 0 1 8}$ \\
Pollen Tubes Lower Style & $0.00 \mathrm{a}$ & $0.00 \mathrm{a}$ & $0.32 \mathrm{~b}$ & $2.19 \mathrm{~b}$ & $\mathbf{0 . 0 1 4}$ \\
\hline
\end{tabular}

$\mathrm{n}=$ number of styles assessed; $\mathrm{ns}=$ no significant difference.

Table 2. - The mean number of pollen grains observed on the stigma and the mean number of pollen tubes in the style of Eucalyptus argophloia using fresh pollen applied directly with anthers, fresh pollen extracted from flowers and pollen that had been stored for 9 months at $5^{\circ} \mathrm{C}$. Means in each row with different letters are significantly different (Kruskal-Wallis).

\begin{tabular}{lllll}
\hline Treatment & $\begin{array}{l}\text { Fresh } \\
(\mathrm{n}=15)\end{array}$ & $\begin{array}{l}\text { Fresh Extracted } \\
(\mathrm{n}=16)\end{array}$ & $\begin{array}{l}\text { Stored } \\
(\mathrm{n}=16)\end{array}$ & $\begin{array}{l}\mathrm{P} \\
\text { value }\end{array}$ \\
\hline Pollen Grains on Stigma & $2.07 \mathrm{a}$ & $2.75 \mathrm{a}$ & $0.0 \mathrm{~b}$ & 0.01 \\
Pollen Tubes Upper style & 1.27 & 0.69 & 0.0 & $\mathrm{~ns}$ \\
Pollen Tubes Mid-Style & 0.67 & 0.19 & 0.0 & $\mathrm{~ns}$ \\
Pollen Tubes Lower Style & 0.47 & 0.69 & 0.0 & $\mathrm{~ns}$ \\
\hline
\end{tabular}

$\mathrm{n}=$ number of styles assessed; $\mathrm{ns}=$ no significant difference. 
adhere to the stigma prior to day 6 , and no pollen tubes were observed in any sample when stigmas were pollinated before this time. Consequently there were significant differences in pollen grain adherences to the stigma and pollen tube growth in the upper, middle and lower style on day 6 compared with all other days $(\mathrm{P}=0.001)$, $(\mathrm{P}=0.001),(\mathrm{P}=0.041)$ and $(\mathrm{P}=0.041)$ respectively.

\section{Comparison of Stored and Fresh Pollen}

Both the fresh and fresh extracted pollen attached to the stigma and showed significantly more adherence to the stigma than stored pollen $(\mathrm{P}>0.01)$ (Table 2$)$. There was no pollen tube growth observed in the stored pollen treatment. There were no significant differences in pollen tube growth between fresh and fresh extracted pollen (Table 2).

\section{Discussion}

We report here the highest early pollination success for Eucalyptus argophloia occurred in the unpollinated AIP treatment, indicating potentially high levels of selfpollination using AIP methods. The stigma became receptive six days after anthesis.

\section{Pollination Methods}

The results show significantly more pollen tubes from unpollinated AIP and AIP treatments than the one-stop pollination and three-stop pollination treatments. Both one-stop pollination and three-stop pollination methods require the stigma to be moist in order for pollen to adhere at pollination. For the one-stop pollination treatment this is after emasculation and excision of the stigma (TRINDADE et al., 2001), and the three-stop pollination treatment at the time of stigma receptivity. Removing the upper style in the AIP method causes formation of exudates and results in pollen adhesion and pollen tube growth in E. globulus (TRINDADE et al., 2001) and $E$. grandis (Assis et al., 2005). Increased pollen tube growth using AIP has been observed in controlled pollination of other Eucalypts subgenus Symphyomyrtus species (E. grandis and E. woodwardii) (HORSLEY et al., 2010).

Pollen tubes from the unpollinated protogyny treatment most likely resulted from self-fertilisation as the buds had been isolated in a pollination bag. High rates of contamination have been recorded in $E$. globulus (Molina et al., 2011), E. grandis, E. macarthii and E. smithii (HoRsLeY et al., 2010) and Corymbia hybrids (DICKINSON et al., 2010) using AIP treatments. Decreased growth performance from inbreeding depression often occurs with self-pollinated seedlings (ElDRIDGE and GRIFFIN, 1983; House, 1997; Pound et al., 2002). Therefore, to undertake pollination experiments that require known parentage, the AIP method is unsuitable for $E$. argophloia due to the risk of self-pollination.

Other studies in small flowered eucalypts found that seed set was lowest using one-stop pollination method and the AIP method produced the highest seed set (HoRsLey et al., 2010). The complete absence of pollen tube growth in the one-stop pollination method and low numbers observed in three-stop pollination may indicate reduced seed production. HoRSLEY et al. (2010) using $E$. grandis, E. smithii and E. macarthurii; species with slightly larger buds than $E$. argophloia, suggested that damage to the flowers of these species during emasculation due to the small size of the flowers was the cause of the reduced seed set. Similarly, damage to $E$. argophloia buds because of the difficulty of emasculating very small buds may have inhibited pollen tube growth.

\section{Timing of Stigma Receptivity}

Our results clearly show that stigma receptivity in $E$. argophloia did not occur until at least six days after anthesis. E. argophloia is clearly protandrous and this influences the timing for controlled pollination. Optimal stigma receptivity varies among eucalypt species, for example, for $E$. grandis is five days after anthesis (HodGson, 1976); for E. spathulata and E. leptophylla is eight days and for E. cladocalyx is ten days (ELLIS and SEDGLEY, 1992); maximum pollen germination in $E$. woodwardii occurred after day seven (SEDGLEY and SMITH, 1989); similarly E. globulus is also receptive after seven days (Pound et al., 2002).

We recommend that controlled pollination of $E$. argophloia be conducted at least six days after anthesis when stigma receptivity commences. The experiment concluded at six days, additional research is required to determine how long the stigma remains receptive.

\section{Comparison of Stored and Fresh Pollen}

During pollination, stigmas produce exudates that allow the male gametophyte to adhere to the stigma (LORD, 2000). After adhesion, the pollen grains are hydrated, germinate and develop pollen tubes that grow down the stigma (LORD, 2000). The viability of pollen is largely dependent on the pollen's reaction to storage methods. In this experiment pollen of $E$. argophloia stored for nine months at $5^{\circ} \mathrm{C}$ failed to adhere to stigmas for the twelve days until the style was harvested and consequently no pollen tube growth occurred in the stored pollen treatment. In contrast both the fresh extracted and fresh pollen direct from the anther attached to the stigma and produced pollen tube growth. In contrast, pollen of $E$. nitens, $E$. smithii and $E$. grandis stored in a freezer for 12 months showed only slightly reduced growth (HoRSLEY et al., 2007). E. nitens and $E$. smithii are from more temperate zones while $E$. grandis, a subtropical to tropical species, was subject to a larger reduction in germination after 12 months at $-196{ }^{\circ} \mathrm{C}$ (HoRsley et al., 2007). Pollen stored at $5{ }^{\circ} \mathrm{C}$ in our experiments produced no pollen tube growth, indicating that the stored pollen was not viable. Different storage methods such as the use of lower temperature storage, including liquid nitrogen may be necessary to maintain viability of $E$. argophloia pollen during storage. The viability of stored pollen should be checked invivo prior to use in a breeding program.

\section{Conclusions}

Stigma receptivity commences in Eucalyptus argophloia at six days after anthesis. The AIP and 
unpollinated AIP techniques were the most successful for pollen tube development in E. argophloia, however, these pollination techniques would also likely produce mainly self-fertilized seedlings. Based on this we suggest that the three stop pollination system be used for controlled pollination of $E$. argophloia in breeding programs, and that stigmas are pollinated at least six days after anthesis. This study also suggests that fresh $E$. argophloia pollen should be used in any crossing program, and other methods of pollen storage be investigated.

\section{Acknowledgements}

The authors wish to acknowledge the Australian Research Council linkage grant number LP0562678 and Forestry Plantations Queensland for financial assistance, John Oostenbrink for technical support and the Department of Employment Economic Development and Innovation Queensland for allowing access to trees.

\section{References}

Assis, T., P. WARburton and C. HaRwood (2005): Artificially induced protogyny: an advance in the controlled pollination of Eucalyptus. Australian Forestry 68: 27-33.

Boland, D., M. Brooker, G. Chippendale, N. Hall, B. Hyland, R. Johnson, D. Kleinig, M. McDonald and J. TURNER (2006): Forest Tree of Australia. CSIRO Publishing, Melbourne.

Brooker, M. and D. Kleinig (2004): Field Guide to Eucalypts - Volume 3 Northern Australia (2 ${ }^{\text {nd }}$ Edition). Bloomings Books, Melbourne.

Delaporte, K. L., J. G. Conran and M. Sedgley (2001): Interspecific hybridization within Eucalyptus (Myrtaceae): subgenus Symphyomyrtus, sections Bisectae and Adnataria. International Journal of Plant Sciences 162: 1317-1326.

Dickinson, G., H. Wallace and D. LeE (2010): Controlled pollination methods for creating Corymbia Hybrids. Silvae Genetica 59: 233-241.

EldRIDGE, K. G. and A. R. GRIFFin (1983): Selfing effects in Eucalyptus regnans, Silvae Genetica 32: 5-6.

ELLIS, M. and M. SEDGLEY (1992): Floral morphology and breeding systems of three species of Eucalypts, section Bisectaria (Myrtaceae). Australian Journal of Botany 40: $249-262$.

Griffin, A. R. and F. C. HAND (1979): Post-anthesis development of flowers of Eucalyptus regnans F. Muell. and the timing of artificial pollination. Australian Forest Research 9: 9-15.

Harbard, J. L., A. R. GRIFFin and J. EspeJo (1999): Mass controlled pollination of Eucalyptus globulus: a practical reality. Canadian Journal of Forest Research 29: 1457-1463.

Hodgson, L. M. (1976): Some aspects of flowering and reproductive behaviour in Eucalyptus grandis at J.D.M. Keet Forestry Research Station. 1. Flowering, controlled pollination methods, pollination and receptivity. South African Forestry Journal 97: 18-28.

Horsley, T., S. Johnson and T. Stanger (2007): Optimum storage and in vitro germination of Eucalyptus pollen. Annals of Botany 55: 83-89.
Horsley, T., S. Johnson and A. MyBurg (2010): Comparison of different control-pollination techniques for smallflowered eucalypts. New Forests 39: 75-88.

House, S. (1997): 'Reproductive biology of eucalypts'. In: Eucalypt Ecology - Individuals to ecosystems. Edited by J. Williams and J. WoINARsKI. Cambridge University Press, Cambridge, UK.

House, S., M. Nester, D. Taylor, J. King and D. HINCHLEY (1998): Selecting trees for the rehabilitation of saline sites in south east Queensland. Department of Primary Industries, Gympie, Queensland.

Lee, D., V. Debuse, P. Pomroy, K. Robson and D. Nikles (2005): Developing genetically adapted tree varieties for marginal areas of northern Australia. Rural Industries Research and Development Corporation, Barton, ACT, Australia.

Lee, D., J. Huth, J. Brawner and G. Dickinson (2009): Comparative performance of Corymbia hybrids and parental species in subtropical Queensland and implications for breeding and deployment. Silvae Genetica 58: 205-212.

LeE, D., J. Huth, D. Osbourne and B. HogG (2010): Selecting hardwood taxa for wood and fibre production in Queensland's subtropics. Australian Forestry 73: 106-114.

Lee, D., J. Brawner, T. Smith, B. Hogg, R. Meder and D. OsBorne (2011): Productivity of plantation forest tree species in north-eastern Australia: A report from the Forest Adaptation and Sequestration Alliance. Australian Government, Department of Agriculture, Fisheries and Forestry, Canberra, Australia. pp 50.

LORD, E. (2000): Adhesion and cell movement during pollination: cherchez la femme. Trends in Plant Science 5: 368-373.

MARTIN, F. (1959): Staining and observing pollen tubes in the style by means of fluorescence. Stain Technology 34: 125-128.

Molina, P., R. Sanheuza and J. Elizaul (2011): Comparison of methods for controlled pollination in hybrids Eucalyptus globulus Labill. In: Proceedings of IUFRO Working Group 2.08.03 'Improvement and Culture of Eucalypts', $14^{\text {th }}-18^{\text {th }}$ November 2011, Porto Seguro, Bahia, Brazil, de moraes J. L. Goncalves et al. (eds.), p. 471. College of Agriculture "Luiz de Queiroz, Sao Paulo. ISSN 2255-594X. http://www.iufro.org/publications/proceedings/proceedings-meetings-2011/

Moncur, M. (1995): Techniques for pollinating eucalypts. ACIAR Technical Reports 34. Australian Centre for International Agricultural Research. 19pp.

Ngugi, M., M. Hunt, D. Doley, P. Ryan and P. Dart (2004a): Selection of species and provenances for lowrainfall areas: physiological responses of Eucalyptus argophloia to seasonal conditions in subtropical Queensland. Forestry Ecology and Management 193: 141-156.

Ngugi, M., D. Doley and M. Hunt (2004b): Physiological responses to water stress in Eucalyptus cloeziana and E. argophloia seedlings. Trees 18: 381-389.

Patterson, B., P. Gore, B. Potts and R. Vaillancourt (2004): Advances in pollination techniques for largescale seed production in Eucalyptus globulus. Australian Journal of Botany 52: 781-788.

PotTs, B. and H. Dungey (2004): Interspecific hybridization of Eucalyptus: key issues for breeders and geneticists. New Forests 27: 115-138. 